Proceedings

\title{
Innovative Solving Process Problems of Micro-Turbine Ma- chining Using Computer-Aided Innovation Method
}

Pu Huang ${ }^{1}$, Gangfeng Wang ${ }^{1, *}$ and Dong Zhang ${ }^{1}$

1 National Engineering Laboratory for Highway Maintenance Equipment, School of Construction Machinery, Chang'an University, Xi'an 710064, China; huangpu0207@163.com (P.H.); zhangdongchd@foxmail.com (D.Z.)

* Correspondence: wanggf@chd.edu.cn

+ Presented at the title, place, and date.

Citation: Lastname, F.; Lastname, F.; Lastname, F. Title. Eng. Proc. 2021, 3, x. https://doi.org/10.3390/xxxxx

Published: date

Publisher's Note: MDPI stays neutral with regard to jurisdictional claims in published maps and institutional affiliations.

Copyright: (C) 2021 by the authors. Submitted for possible open access publication under the terms and conditions of the Creative Commons Attribution (CC BY) license (http://creativecommons.org/licenses /by/4.0/).

\begin{abstract}
With the increasingly fierce competition in the global market, technological innovation is regarded as an important factor for manufacturing companies to ensure their future competitive advantages. Modern mechanical design and manufacturing technology has become the mainstream trend of the machinery industry, and the rise of micro-processing production technology is an unstoppable international trend. Therefore, the machinery manufacturing industry must increase its efforts to develop and update micro-processing production technology, and keep up with the pace of upgrading of the machinery industry. At present, most of the processing technology innovation activities are highly dependent on the personal knowledge accumulated for a long time in the previous projects, and the success rate of the innovative methods is low. TRIZ theory (Theory of Inventive Problem Solving) provides a systematic theory and method tool for people to discover and solve problems creatively, due to TRIZ theory is mainly applicable to product innovation design, it lacks specific parameters and principles for process innovation. In recent years, the ComputerAided Process Innovation (CAPI) introduced on the basis of computer technology provides designers with an effective way to obtain process innovation inspiration and improve process technology innovation efficiency. This paper takes the innovative solution of the micro-turbine machining process problem as an example to verify the effectiveness of the computer-aided process innovation solution method.
\end{abstract}

Keywords: Process innovation; Micromachining; CAPI; TRIZ theory; Micro-turbine

\section{Introduction}

With the development of manufacturing technology, modern manufacturing enterprises pay more attention to the machining precision of complex products[1,2]. In the fields of electronics, aviation or medical equipment, the use of micro-machining technology is undoubtedly the most effective measure in the processing of small or micro workpieces[3,4]. The use of reasonable processing procedures and processing methods is of great significance for manufacturing companies to reduce manufacturing costs, improve product quality, and gain competitive advantages[5]. Therefore, manufacturing companies pay more attention to technological innovation and its knowledge of technological innovation, and process innovation is the guarantee for the realization of product innovation. Process innovation refers to the comprehensive application of various knowledge, discovering technical contradiction in the process problems to be resolved, and gradually eliminating this process contradiction based on the basic scientific principles of contradiction resolution, thereby forming new or improved process methods[6-8]. Manufacturing companies can improve production, increase efficiency, reduce consumption, and promote new product manufacturing or major product improvements through process innovation or improvement. At the same time, manufacturing companies can also achieve 
industrial transformation and upgrading through process innovation[9,10]. However, the current manufacturing companies process innovation activities in the processing process are mainly dependent on the experience accumulated by individuals in the previous projects, and the efficiency and success rate of innovation are low [11,12].

TRIZ (Theory of Inventive Problem Solving) is a knowledge-based, human-oriented, and systematic method of solving invention problems[13]. However, TRIZ theory is more inclined to product innovation design, and lacks specific parameters and principles in process innovation[14,15]. In recent years, the Computer-Aided Process Innovation (CAPI) introduced on the basis of computer technology provides designers with an effective way to obtain process innovation inspiration and improve process technology innovation efficiency[5].

In this paper, we adopt computer-aided process innovation technology to solve the innovative solution of micro-turbine machining process, in order to improve the rationality of the micro-turbine machining process and the machining efficiency.

\section{Methods of Process Innovation}

Process Innovation Knowledge (PIK) is considered to be the knowledge that runs through the entire cycle of process innovation activities to support the efficient and correct realization of process innovation activities and form new or improved process methods[6,16]. PIK can be obtained from the theoretical basis, process principles, technology patents and innovation cases, expert experience, innovation theory, etc. On the basis of formal innovation knowledge representation, different types of innovation knowledge units need to be further associated and organized, and a dynamic innovation knowledge network should be constructed to effectively inspire process designers to carry out structured innovation design in the complex manufacturing process problem solving scenarios.

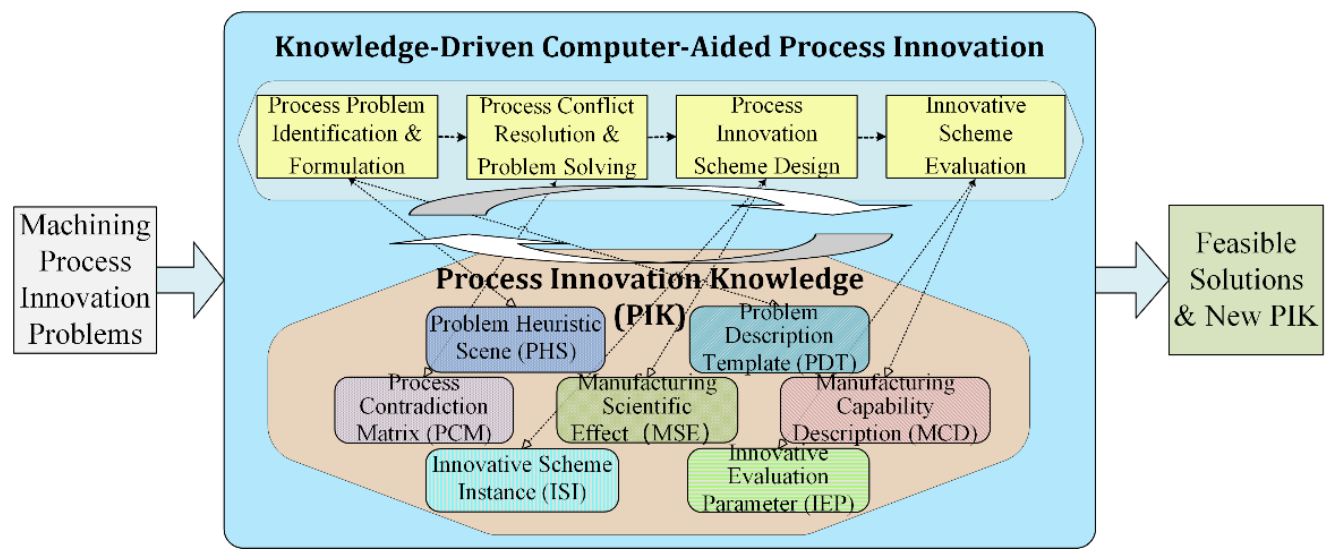

Figure 1. The procedure of knowledge-driven computer-aided process innovation

The procedure of knowledge-driven computer-aided process innovation design as shown in Figure 1. Different types of machining PIK must be applied to the corresponding innovation design stage. Thus, machining PIK can be divided into the following types to support the entire process of innovation design: Problem Heuristic Scene (PHS), Problem Description Template (PDT), Process Contradiction Matrix (PCM), Manufacturing Scientific Effect (MSE), Innovative Scheme Instance (ISI), Innovative Evaluation Parameter (IEP), and Manufacturing Capability Description (MCD). The procedure of process innovation design can be divided into four steps that include: process problem identification and formulation, process conflict resolution and problem solving, process innovation scheme design, and innovative scheme evaluation. The purpose of the innovation process is to identify contradictions in problems and resolve them with dialectical thinking. The follows this approach and receives widespread attention due to its structured procedure of problem-solving. In the process problem identification step, typical problem scenarios have heuristic features and can help technicians to improve the efficiency and quality of 
problem recognition. In the innovative scheme evaluation step, the feasibility of innova- 1 tive solutions require evaluation according to the evolution law of technology systems 2 and the manufacturing capacity of the corresponding enterprise.

\section{Innovative Solution to the Machining Process of Micro-Turbine}

A micro-turbine is a high-precision turbojet engine part, which is mainly composed of a hub, several sets of blades evenly distributed along the circumference of the hub, and hub grooves on both ends. Its structure can be seen in Figure 2. The micro-turbine blade is thin and has a twisted profiled surface, and the center of the turbine has a through-hole structure, the workpiece is difficult to clamp.

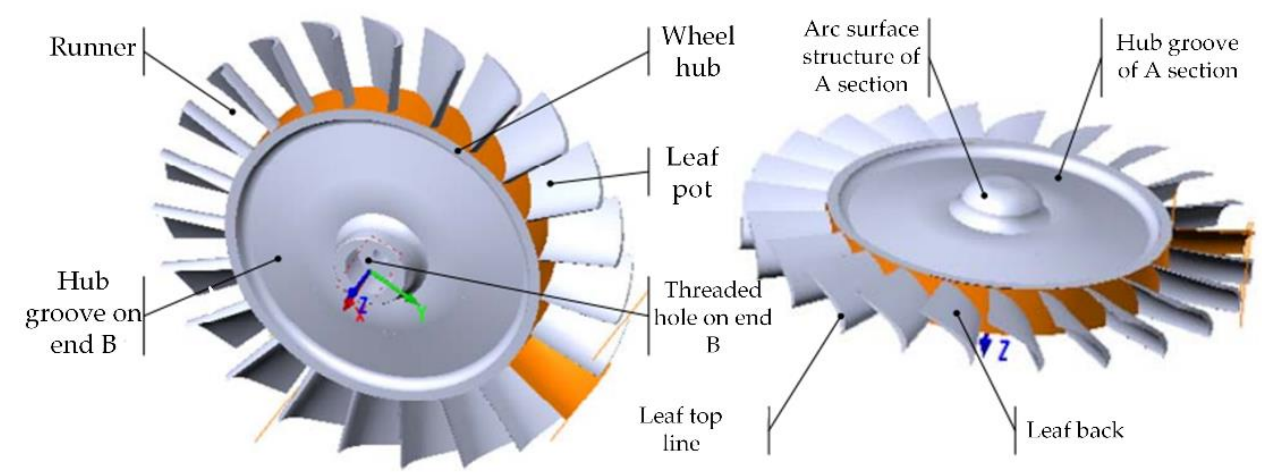

Figure 2. Schematic diagram of a micro turbine structure.

\subsection{The Machining Process of a Micro-Turbine}

The CNC (Computer Numerical Control) machine tool comes with a four-jaw chuck. However, both ends of the turbine have bosses and arc structures with a height of only about $4 \mathrm{~mm}$. The four-jaw chuck cannot directly and effectively clamp these two structures when machining turbine blades. When the micro-turbine is processing the blades, after the two end faces of the micro-turbine are processed, a through hole is usually drilled in the center of the turbine to clamp the turbine. In fact, this method is a machining method for turbines with through-hole structures. For turbines without through-holes, this method will destroy the structural integrity of the parts themselves. In addition, the positioning of the mandrel adopts clearance fit, and the vibration generated during the machining process makes it difficult to ensure the accuracy of the blade. The processing of the micro turbine blade is the key to the processing of the part, and the reliable clamping of the workpiece can ensure the size and shape accuracy of the blade.

\subsection{Solving the Machining Process Problem of a Micro-Turbine}

(1) Formal description of process problems.

As shown in Figure 3, in accordance with the requirements of the PDT designed by CAPI, the process designer formalizes the process problem in SVOP (Subject-Verb-ObjectParameter) format as: expect "turbine + maintenance + structure + unchanged/complete" and avoid "fixture + improvement + complexity + significant". 


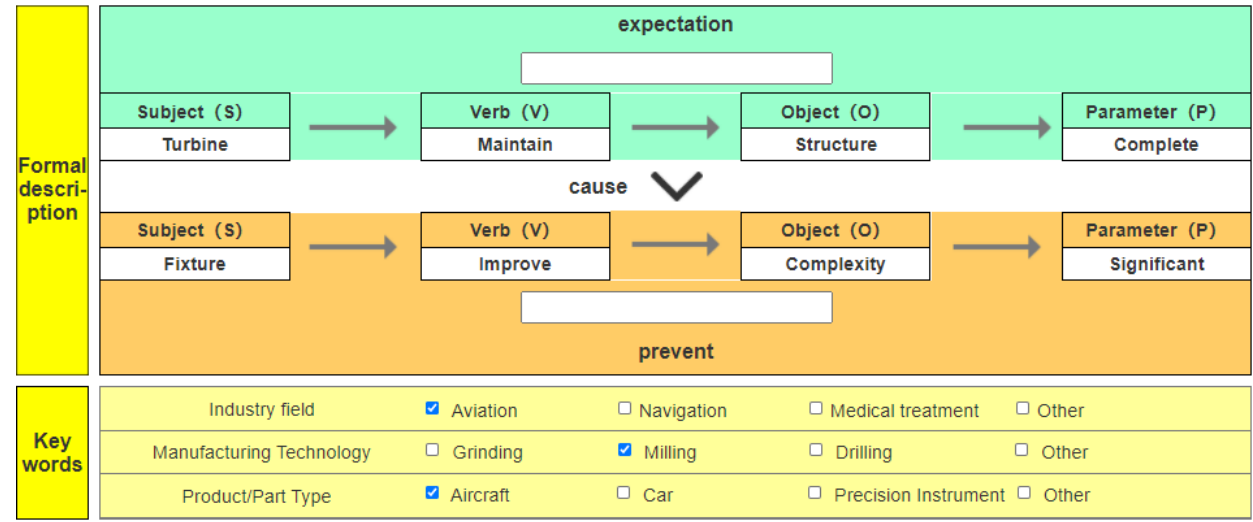

Figure 3. Formal description of micro-turbine process problems.

(2) Obtaining ideas for solving process problems.

After the process problem description is completed, the system will automatically match the innovation principle according to the input formal content to solve the corresponding knowledge unit in the PCM, and give the corresponding original understanding of the innovation.

As shown in Figure 4, the process contradiction parameters are obtained from the above problem description system, where the strengthening parameter is "workpiece structure" and the weakening parameter is "fixture complexity". The corresponding solution principles are: split structure/function; transform structure form/function; extract useful structure/function; adopt periodic actions; adopt porous materials. In addition, the system gives the corresponding classic TRIZ solution principles according to the problem description: Divide; Copy; Use cheap ones instead of expensive ones. When the given process solution principle does not help to solve the problem, you can choose the TRIZ solution principle to inspire the problem solving.

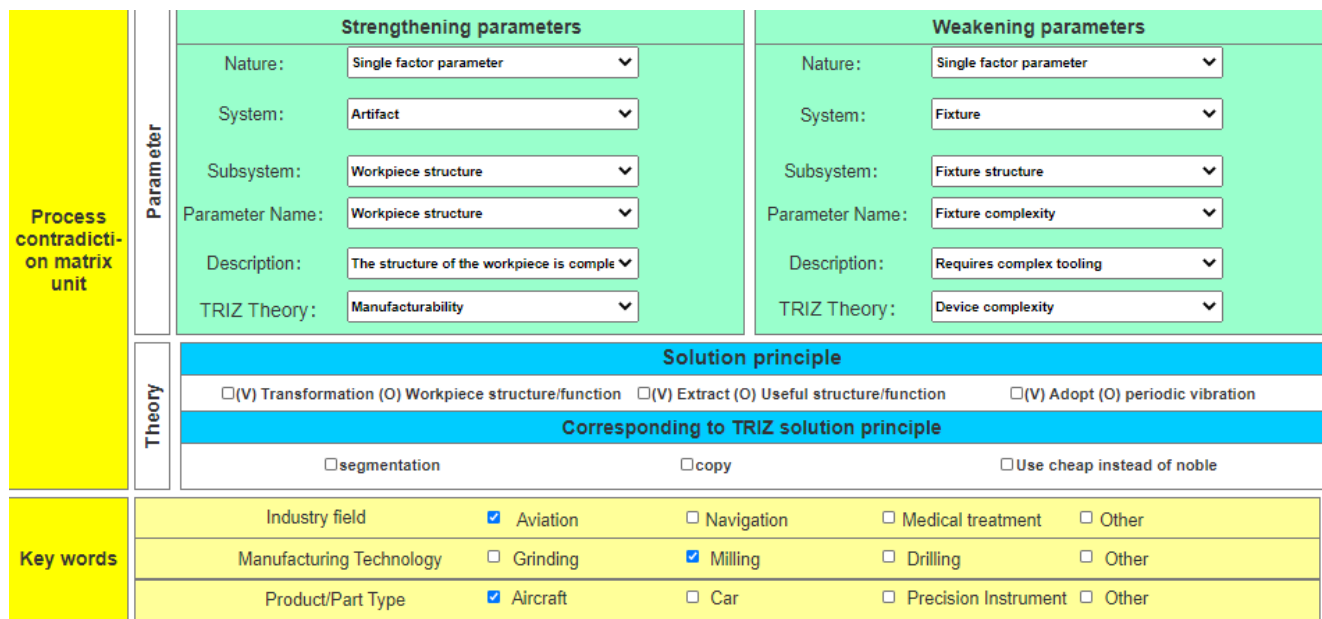

Figure 4. Get the principle of solving the micro-turbine process problem.

Based on the above analysis, it is believed that splitting the structure/function, adopting periodic actions, and adopting porous materials have basically no contribution to the solution of technological problems, the two innovative principles of transforming structure form/function and extracting useful structure/function are inspiring for solving process problems. Among them, the transformation of structural form/function contributes a lot to the solution of this problem. The inspiration is: In addition to the blades of the microturbine, the available parts are the arc bosses and threaded hole structures on both ends of $\mathrm{A}$ and $\mathrm{B}$, which can be transformed into structures or functions. Therefore, tick the enlightening solution principle, and select the corresponding industry field, manufacturing 
technology and product parts and other keywords, and the system will give the corresponding manufacturing science effect (MSE) to further clarify the innovative ideas, as shown in Figure 5.

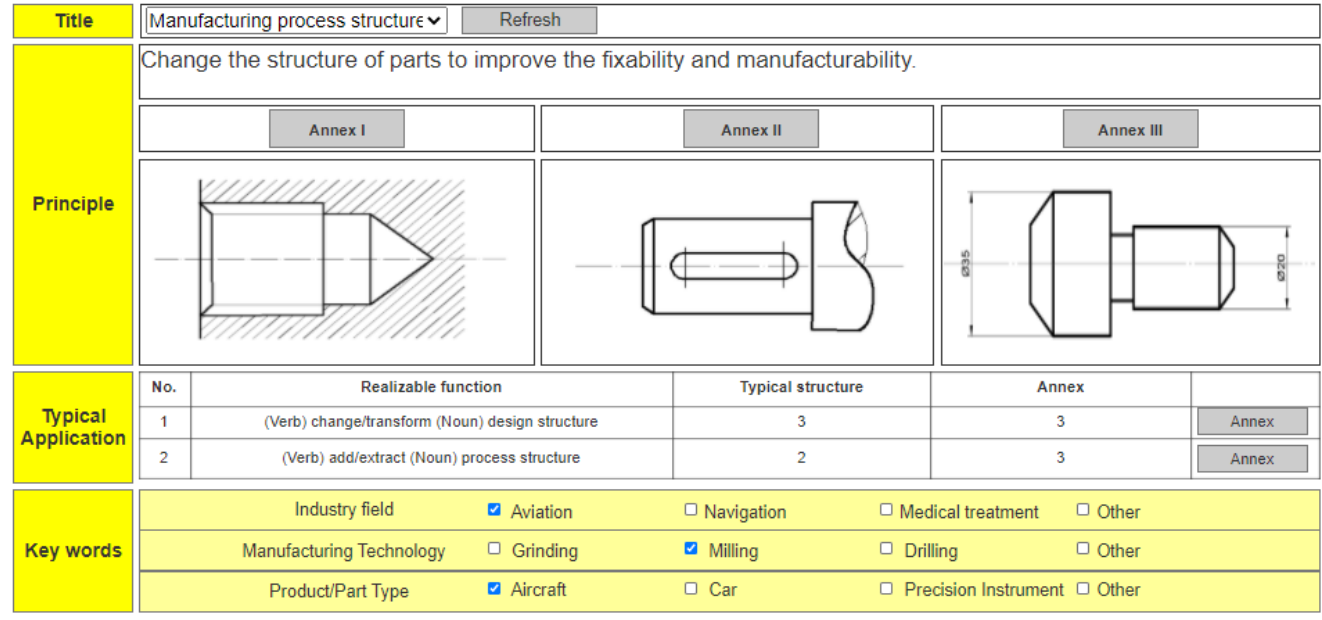

Figure 5. The manufacturing science effect corresponding to the micro-turbine process problem.

Based on the enlightenment given by the effects of manufacturing science, the solution provided for the problem of functional "change/transformation of design structure" is: The final feature of the arc surface structure of the end face of the micro turbine A is first transformed into a form that can provide clamping, that is, change its form and function under the processing environment, for the four-jaw chuck to be clamped, after the turbine blade is processed, it is processed to the standard size required by the part. Therefore, the integral structure of the clamping process boss can avoid the problem of low blade processing quality caused by gap vibration.

(3) Iterative solution of micromachining process problems.

After the turbine blade is processed, the reserved process boss on the end face of the turbine A needs to be reduced to a circular arc surface structure. At this time, the blade has been finished, if the pressure plate is used to clamp the turbine, it is easy to clamp the finished blade or even cause the deformation of the blade. If the turbine blade is not clamped, it will be impossible to clamp when the process boss is cut off. Therefore, the machining quality of the turbine blades and the clampability of the turbine constitute a contradiction, which requires another innovative solution. According to the above-mentioned problem analysis process, according to the PDT format requirements, the problem is formalized as: expect "workpiece + improvement + fixability + moderate" and avoid "fixture + destruction + workpiece quality + significant". Then, the solution principle of the strengthened parameter "workpiece clampability" and the weakened parameter "workpiece manufacturing quality" are obtained from PCM: Split structure/function; Transform structure form/function; Use one's own structure/function. After analysis, it is believed that transforming structural form/function and using one's own structure/function have a greater contribution to problem solving. However, the process boss on the A end face improves the processing quality of the blade but causes the current problem. The form or function of the threaded hole structure on the B end face is used as the direction to solve the problem. Combining the use of its own structure/function can form a solution to this problem: use the threaded hole structure of the B end face used in the assembly of the final product in the clamping and positioning of the workpiece. Therefore, it is possible to make full use of the counterbore and thread of the workpiece itself, and self-made tooling with threaded connection to cooperate with it, thereby milling the technological boss and processing it into the final shape. In addition, the use of its own structure/function can also indicate the direction of the tool path, even if the milling direction of the tool is the thread tightening direction, the cutting force during the machining process is used to 
make it spin and lock, realize the positioning and clamping of the turbine and provide 1 guarantee for cutting off the boss.

(4) Innovative scheme design and machining test.

Under the guidance of the above-mentioned innovative principles and solutions, a simple self-made tooling was designed to realize the clamping and positioning of a certain micro-turbine blade (Part 4 in Figure 6). The clamping and machining plan of the turbine was designed in detail, and a complete technological process was formed. Then, the software was used for numerical control programming, and the machining experiment of the micro turbine was carried out using the carved SmartCNC500 five-axis linkage numerical control machine tool, as shown in Figure 6. Figure 7 shows the comparison of the turbine blade processing effect between the process innovation design scheme and the original mandrel positioning scheme. It can be seen from the figure that the innovative design scheme after the clamping method is changed, the clamping positioning becomes reliable, the vibration during the machining process is small, the surface quality of the blade is obviously improved, and the tool does not produce cutting interference.

1.Milling micro-turbine A end face to form process boss

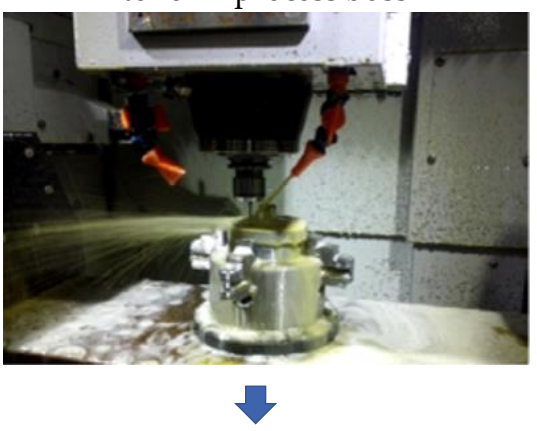

2.Clamping process boss milling the end face of micro-turbine $B$

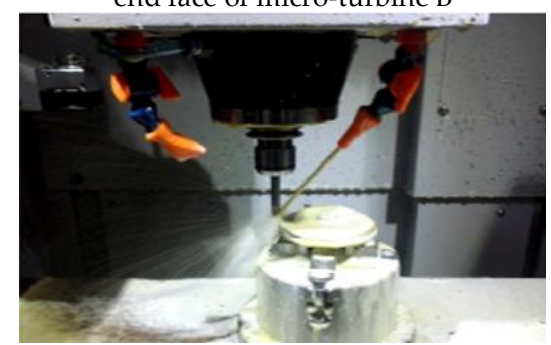

4.Simple clamping and self-made tooling for milling arc surface of micro turbine A end face

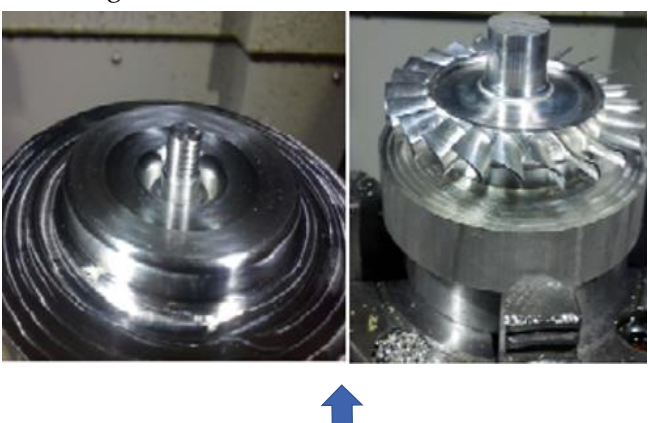

3.Clamping process boss milling micro turbine

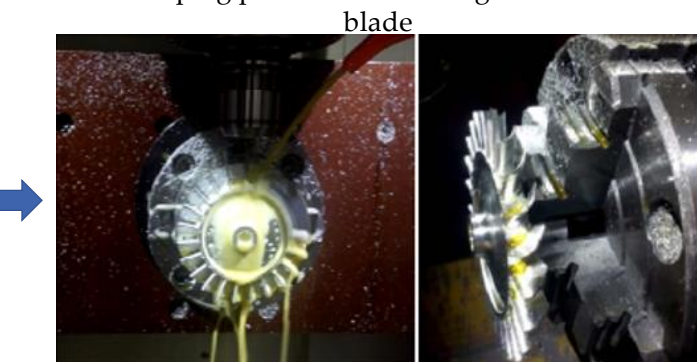

Figure 6. The basic process flow of micro-turbine machining.

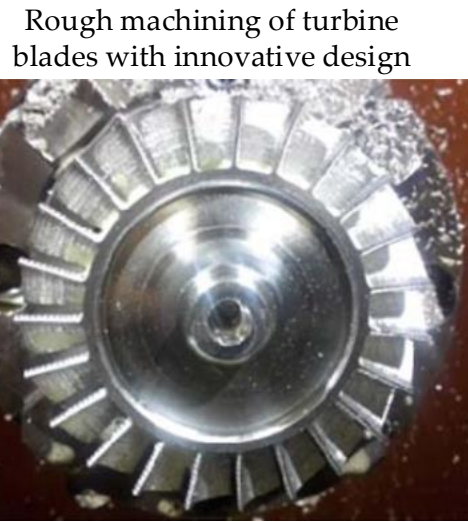

(a)
The rough machining turbine blade of the original plan

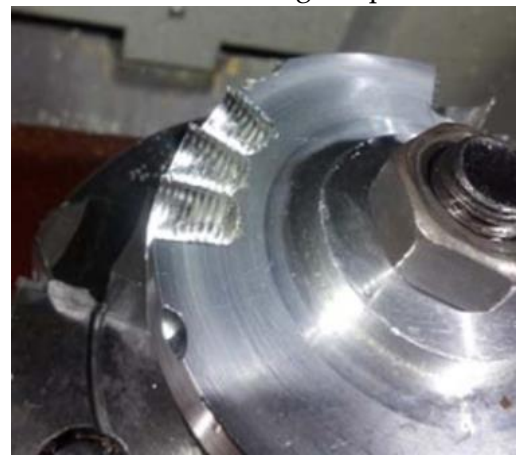

(b)

Figure 7. Comparison of rough machining quality of micro turbine blades. 


\section{Conclusion}

Based on computer-aided technology, this paper establishes a formal representation model of process contradiction matrix, and proposes a process contradiction matrix construction method that obtains principle and innovative knowledge from process patents. This method not only improves the process accuracy of micro-turbine machining, but also avoids deformation. At the same time, it is of great significance to stimulate the innovative thinking of craftsmen and assist the knowledge-based systematic technological innovation design, thereby reducing the randomness, trial and error and technical difficulty of technological innovation activities, and improving the efficiency and success rate of technological innovation.

Author Contributions: Conceptualization, G.W.; methodology, G.W.; software, P.H. and D.Z.; formal analysis, P.H. and D.Z.; writing - original draft preparation, P.H.; funding acquisition, G.W. All authors have read and agreed to the final version of the manuscript.

Funding: This work was supported in part by the Natural Science Basic Research Project of Shaanxi Province, China (Grant No. 2019JM-073), the China Postdoctoral Science Foundation (Grant No. 2018M633439).

Data Availability Statement: No new data were created or analyzed in this study. Data sharing is not applicable to this article.

Conflicts of Interest: The authors declare no conflict of interest.

\section{References}

1. Feng, Y.X.; Zhao, Y.L.; Zheng, H.; Li, Z.W.; Tan, J.R. Data-driven product design toward intelligent manufacturing: A review. Int. J. Adv. Rob. Syst. 2020, 17, 1729881420911257.

2. Moslemipour, G.; Lee, T.; Rilling, D. A review of intelligent approaches for designing dynamic and robust layouts in flexible manufacturing systems. Int. J. Adv. Manuf. Tech. 2012, 60, 11-27.

3. Ba, S.; Jain, N.; Joseph, V.R.; Singh, R. Integrating Analytical Models with Finite-Element Models: An Application in Micromachining. Journal of Quality Technology 2013, 45, 200-212.

4. Lalakiya, M.R. Micromachining process-current situation and challenges. In 2015 2nd International Conference on Mechatronics and Mechanical Engineering, Tandon, P.; Guo, M., Eds. 2015; Vol. 34.

5. Wang, G.; Tian, X.; Geng, J.; Guo, B. A knowledge accumulation approach based on bilayer social wiki network for computer-aided process innovation. Int. J. Prod. Res. 2015, 53, 2365-2382.

6. Wang, G.; Hu, Y.; Tian, X.; Geng, J.; Hu, G.; Zhang, M. An Integrated Open Approach to Capturing Systematic Knowledge for Manufacturing Process Innovation Based on Collective Intelligence. Appl. Sci. 2018, 8, 340.

7. $\quad$ Carbone, F.; Contreras, J.; Hernández, J.Z.; Gomez-Perez, J.M. Open Innovation in an Enterprise 3.0 framework: Three case studies. Expert. Syst. Appl. 2012, 39, 8929-8939.

8. Chinkatham, T.; Cavallucci, D. Early feasibility evaluation of Solution Concepts in an Inventive Design Method Framework: Approach and support tool. Comput. Ind. 2015, 67, 1-16.

9. Dooley, L.; O'Sullivan, D. Systems innovation: Managing manufacturing systems redesign. Int. J. Computer Integr. Manuf. 2000, 13, 410-421.

10. Molcho, G.; Zipori, Y.; Schneor, R.; Rosen, O.; Goldstein, D.; Shpitalni, M. Computer aided manufacturability analysis: Closing the knowledge gap between the designer and the manufacturer. CIRP Ann-Manuf. Techn. 2008, 57, 153-158.

11. Al-wswasi, M.; Ivanov, A.; Makatsoris, H. A survey on smart automated computer-aided process planning (ACAPP) techniques. Int. J. Adv. Manuf. Tech. 2018, 97, 809-832.

12. Cardoso, P.; Davim, J.P. Optimization of Surface Roughness in Micromilling. Mater. Manuf. Processes 2010, 25, 1115-1119.

2 3 4 5 6 
13. Chechurin, L.; Borgianni, Y. Understanding TRIZ through the review of top cited publications. Comput. Ind. 1 2016, 82, 119-134.

14. Cascini, G. TRIZ-based anticipatory design of future products and processes. Journal of Integrated Design and Process Science 2012, 16, 29-63.

15. Vinodh, S.; Kamala, V.; Jayakrishna, K. Integration of ECQFD, TRIZ, and AHP for innovative and sustainable product development. Applied Mathematical Modelling 2014, 38, 2758-2770.

16. Wang, G.; Tian, X.; Hu, Y.; Evans, R.D.; Tian, M.; Wang, R. Manufacturing Process Innovation-Oriented Knowledge Evaluation Using MCDM and Fuzzy Linguistic Computing in an Open Innovation Environment. Sustainability 2017, 9, 1630. 